\title{
Optimisation of energy supply at off-grid healthcare facilities using Monte Carlo simulation
}

\author{
Rodolfo Dufo-López ${ }^{\mathrm{a}^{*}}$, Eduardo Pérez-Cebolladaa ${ }^{\mathrm{a}}$ José L. Bernal-Agustín ${ }^{\mathrm{a}}$, Ignacio Martínez-Ruiz \\ aElectrical Engineering Department, University of Zaragoza \\ Calle María de Luna, 3. 50018-Zaragoza, Spain \\ E-mail: rdufo@unizar.es, perez.cebollada@gmail.com, jlbernal@unizar.es \\ ${ }^{\mathrm{b} C o m m u n i c a t i o n s ~ T e c h n o l o g i e s ~ G r o u p ~(G T C), ~ A r a g o ́ n ~ I n s t i t u t e ~ o f ~ E n g i n e e r i n g ~ R e s e a r c h ~(I 3 A) ~}$ \\ Calle María de Luna, 3. 50018-Zaragoza, Spain \\ E-mail: imr@unizar.es
}

\begin{abstract}
In this paper, we present a methodology for the optimisation of off-grid hybrid systems (photovoltaic-diesel-battery systems). A stochastic approach is developed by means of Monte Carlo simulation to consider the uncertainties of irradiation and load. The optimisation is economic; that is, we look for a system with a lower net present cost including installation, replacement of the components, operation and maintenance, etc. The most important variable that must be estimated is the batteries lifespan, which depends on the operating conditions (charge/discharge cycles, corrosion, state of charge, etc.). Previous works used classical methods for the estimation of batteries lifespan, which can be too optimistic in many cases, obtaining a net present cost of the system much lower than in reality. In this work, we include an advanced weighted Ah-throughput model for the lead-acid batteries, which is much more realistic.
\end{abstract}

The optimisation methodology presented in this paper is applied in the optimisation of the electrical supply for an off-grid hospital located in Kalonge (Democratic Republic of the Congo). At the moment, the power supply relies on a diesel generator; batteries are used in order to ensure the basic supply of energy when the generator is unavailable (night hours). The optimisation includes the possibility of adding solar photovoltaic (PV) panels to improve the supply of electrical energy. The results show that optimal design could achieve a $28 \%$ reduction in the levelised cost of energy and a 54\% reduction in the diesel fuel used in the generator, thereby reducing pollution. Furthermore, we discuss possible improvements to the telecommunications of the hospital.

Keywords: Photovoltaic, Diesel, Batteries, Monte Carlo simulation, Off-grid hospital.

*Corresponding author. Tel.:+34876555124; fax:+34976762226.

E-mail address: rdufo@unizar.es (Rodolfo Dufo-López). 


\section{Introduction}

Several renewable energy sources, such as Photovoltaic (PV), wind etc., can be used to generate electricity, and their application fields are numerous. In this paper, our study focuses on the area of health. In particular, our study case considers a hospital located far off the electric grid.

Previous studies from other authors show several factors that hinder rural electrification in some geographical locations [1-9]. In addition, systems based on renewable sources can be very useful in mobile health emergency systems [10]. These works have demonstrated that the use of renewable energies reduces economic costs and environmental impact, but there are surprisingly few studies of the energy supply to off-grid hospitals [11] in spite of the importance of this type of facility in the health and development of populations that need to receive suitable medical attention.

The simulation and optimisation of stand-alone (off-grid) hybrid systems (usually photovoltaic panels and/or wind turbines and/or diesel genset) with energy storage (usually batteries) have been studied in many works [12-16]. Usually, the optimisation is considered as a minimisation of the levelised cost of energy (LCE), but in some cases two or more variables have been considered in the optimisation [17].

In most of the previous works, the optimisation is used considering a deterministic approach (no randomness is considered in the data). However, some studies have used a stochastic approach to optimise the system, considering the uncertainties in renewable sources and, in some cases, in the load. For example, Kamjoo et al.[18], show a method based on chance-constrained programming $(\mathrm{CCP})$ used to optimise a PV-wind-batteries system, including the uncertainties in renewable sources, using Monte Carlo simulation for validating the results. Arun et al. [19] perform the optimisation of a PV-batteries system using Monte Carlo simulation including the uncertainty associated with solar irradiation. Kamjoo et al. [20] use genetic algorithms to obtain multi-objective optimisation of PV-wind-batteries systems considering uncertainties by means of CCP, comparing the results with Monte Carlo simulation. Maheri, in [21], evaluates the reliability of different PV-wind-batteries-diesel systems obtained by deterministic design, considering two objectives, cost and reliability; in [22], the same author proposes two algorithms (using Monte Carlo simulation) to obtain the optimum margin of safety.

Those previous studies have correctly used the stochastic approach, but all of them use lowaccuracy models for the estimation of the lifespan of the batteries, which usually are the most expensive components (considering the whole lifespan of the system). None of the previous works uses an accurate model for the ageing of the batteries, and the estimation of their lifespan can be too optimistic, implying that the total net present cost of the system (NPC) and the LCE can be very different from the real ones. The battery lifetime has always been estimated in fixed values or using classical models such as the number of equivalent full cycles or the cycle 
counting method; these models assume that operating conditions are those used in standard tests, and they can predict very high battery lifespans, much higher than real ones. In [23], Dufo-López and Bernal-Agustín compare different ageing models for lead-acid batteries, concluding that the weighted Ah-throughput model shown by Schiffer et al. in [24] is much more accurate than the classical models.

In the present paper, a new methodology for the optimisation of stand-alone hybrid systems is shown. The methodology includes a probabilistic optimisation by means of Monte Carlo simulation, in order to consider the uncertainties in the renewable sources and in the load. It allows stochastic optimisation of complex hybrid systems with a high level of accuracy in the model of the system, including a very accurate weighted Ah-throughput model for the lead-acid batteries [24].

This methodology is applied for the optimisation of the electrical supply of a hospital located far off the electric grid in Kalonge (Democratic Republic of the Congo), which is currently powered by a diesel-battery system. The results show that it is possible to improve the current system by adding photovoltaic solar energy, achieving lower total cost and pollutant emissions.

It is necessary to consider the consumption requirements when the main objective is to supply electric power for the needs of an off-grid hospital, its medical services and newer technologies which advance the services through lower-consumption devices (gateways, PCs, tablets, smartphones). In this last case, it would be possible to create a wireless sensor network (WSN), where several sensors record information regarding the physiological variables of the patient to send it to the medical specialist located in another hospital. These devices are sometimes placed in the body of the patient, forming a body sensor network (BSN). They can be machine to machine (M2M) and therefore work without human intervention. They are equipped with a small processor, a radio transceiver for communication and a sensor. Usually, these devices consume very low electrical power (in the range of $\mathrm{mW}$ ) [25].

This work is presented as follows:

- Methodology

- Characteristics of the system to supply electricity to an off-grid hospital in Congo

- Simulation and optimisation results

- Conclusions and future works

\section{Methodology}

A new methodology for the simulation and optimisation of stand-alone hybrid systems (PV+diesel+batteries) has been applied, based on iHOGA software (developed by one of the authors [26]), adding Monte Carlo simulation to perform the stochastic approach. 
The simulation and optimisation used in iHOGA software using a deterministic approach is shown in [26-28]. Recently, the advanced weighted Ah-throughput model for lead-acid batteries was added [24]. The software uses hourly time series for irradiation, temperature, load etc. during a whole year (8,760 values for each data series). With these data series, for each combination of components (number and type of PV panels, number and type of batteries, type of diesel generator, type of inverter-charger) and control strategies, it simulates the performance of the system. Furthermore, it obtains results on the series of energy delivered by the PV, the energy supplied by the diesel, fuel consumption, charge and discharge power of the batteries, remaining capacity of the batteries, etc. At the end of the simulation of each combination of components and control strategies, it evaluates the lifespan of the batteries (number of years to replace them), the total fuel consumption and all the costs involved in the system until it reaches its lifetime (usually 25 years, the PV panel expected lifespan). The costs include replacement of one of the components during the system lifetime. The cash flows of the different years are converted to the first year of the lifetime of the system (considering interest rate and inflation), calculating the NPC. This value divided by the total energy supplied to the load during the system lifetime yields the LCE. The combination of components and control strategies which has the lowest NPC (and also the lowest LCE) is the optimal system. In many cases, the number of possible combinations of components and control strategies is so high that evaluating all of them would imply an unacceptable computation time; in these cases, iHOGA uses a heuristic technique (evolutionary algorithm) to obtain the optimal solution (or a solution near the optimal) in a reasonable computation time [27].

Monte Carlo simulation adds to the software the availability to perform the stochastic approach. In PV-diesel-battery systems, the variability of the mean values of expected irradiation and load (consumption) is very important because it greatly influences the unmet load, the total cost and many other results. In general, the average values of irradiation and load vary from year to year so that its probability distribution follows a normal or Gaussian curve distribution. For example, in Fig. 1, the probability density function (PDF) of the annual average daily irradiation in a specific location is shown in red, and in green we can see the Gaussian curve which best fits. In this case, the mean of the annual average daily irradiation is $5 \mathrm{kWh} / \mathrm{m}^{2} /$ day, and the standard deviation is $0.2 \mathrm{kWh} / \mathrm{m}^{2} /$ day. That means that in most years, the average daily irradiation will be around $5 \mathrm{kWh} / \mathrm{m}^{2} /$ day; however, there may be years with a higher average value and others with a lower average value. For example, the annual average values during 10 consecutive years could be $5.1,4.8,5,4.7,4.5,5.2,5,4.9,5.05$ and $5.1 \mathrm{kWh} / \mathrm{m}^{2} /$ day. 


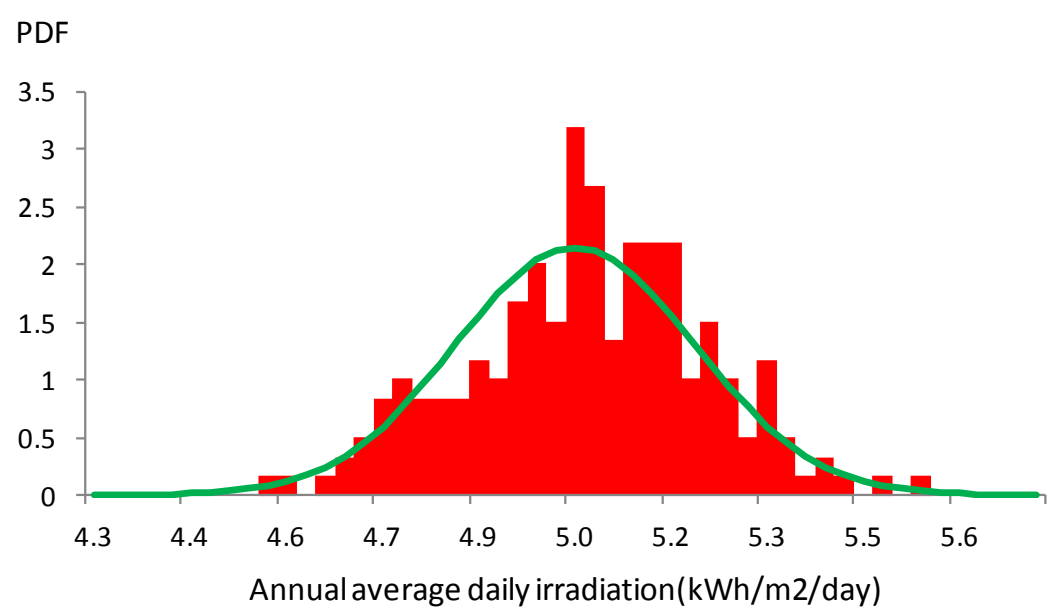

Fig. 1. PDF of the annual average daily irradiation

Therefore, if we know the mean and standard deviation of the average values of these variables, we can perform a probabilistic analysis using Monte Carlo simulation, carrying out different combinations that follow the probability curves of the average values of different variables.

With this analysis, for each combination of components and control strategy to study, there will be $\mathrm{N}$ samples of hourly series of the variables we want to analyse (in this case, load and irradiation). There are efficient methods for obtaining the sample, as, for example, the Monte Carlo variance reduction (MCVR) technique [29,30], but in this work the computing time is not too long, and it has not been necessary to apply these techniques. Each hourly series $(8,760 \mathrm{~h})$ of load and irradiation has an average value obtained according to a Gaussian probability distribution, with the mean the annual average value obtained from measures of many years (usually more than 10 years) and its standard deviation. During optimisation, each combination of components and control strategies is simulated $\mathrm{N}$ times. Each of these simulations includes an hourly series of load consumptions (with average value obtained randomly following the load Gaussian probability function) and a random series of irradiation (with average value obtained randomly following the irradiation Gaussian probability function). Each of these $\mathrm{N}$ simulations gives results of NPC, LCE, emissions, unmet load, energy delivered by PV, fuel consumption, etc. For each result, iHOGA calculates the mean and standard deviation of the $\mathrm{N}$ simulations. The optimal system will be the one with the lowest mean of the NPC.

Usually, the number of samples or trials (or sample size), N, is not a fixed number. There are many convergence thresholds for Monte Carlo simulation so that when the convergence threshold has been reached, the simulation finishes [31-33]. 
A widely used rule is to let the simulation run until the relative standard error of the NPC (standard error of the mean divided by the mean) reaches a specified value RSE (for example, $1 \%)$. This rule is indicated in Eq. (1).

$$
100 \frac{\frac{N P C_{\mathrm{SD}}}{\sqrt{n}}}{N P C_{\text {mean }}}<R S E
$$

where $N P C_{\text {mean }}$ and $N P C_{\mathrm{SD}}$ are the mean and standard deviation of the $N P C$ obtained in the $n$ samples evaluated until now. In this work, we have implemented this method.

Fig. 2 shows the optimisation flowchart that reflects the procedure described above.

COMBINATIONS OF COMPONENTS AND CONTROL STRATEGIES

\section{Data:}

- PV panel types, number min. and max.

- Battery types, number min. and max.

- Diesel generator types

- Inverter-charger types

- Number of control strategies

Combinations of components and control strategies starts $i=0$

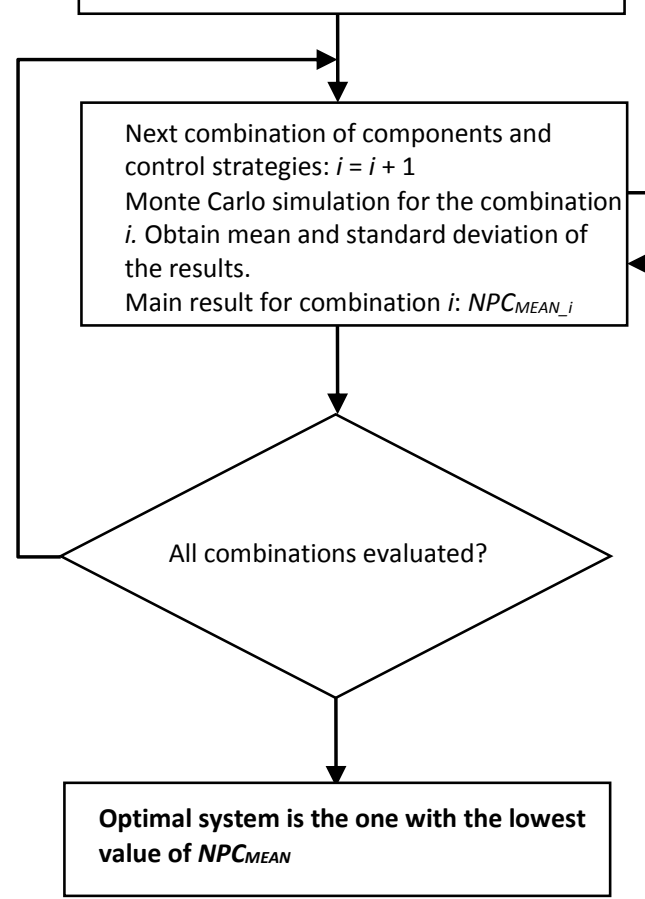

MONTE CARLO SIMULATION FOR EACH COMBINATION i OF COMPONENTS AND CONTROL STRATEGIES

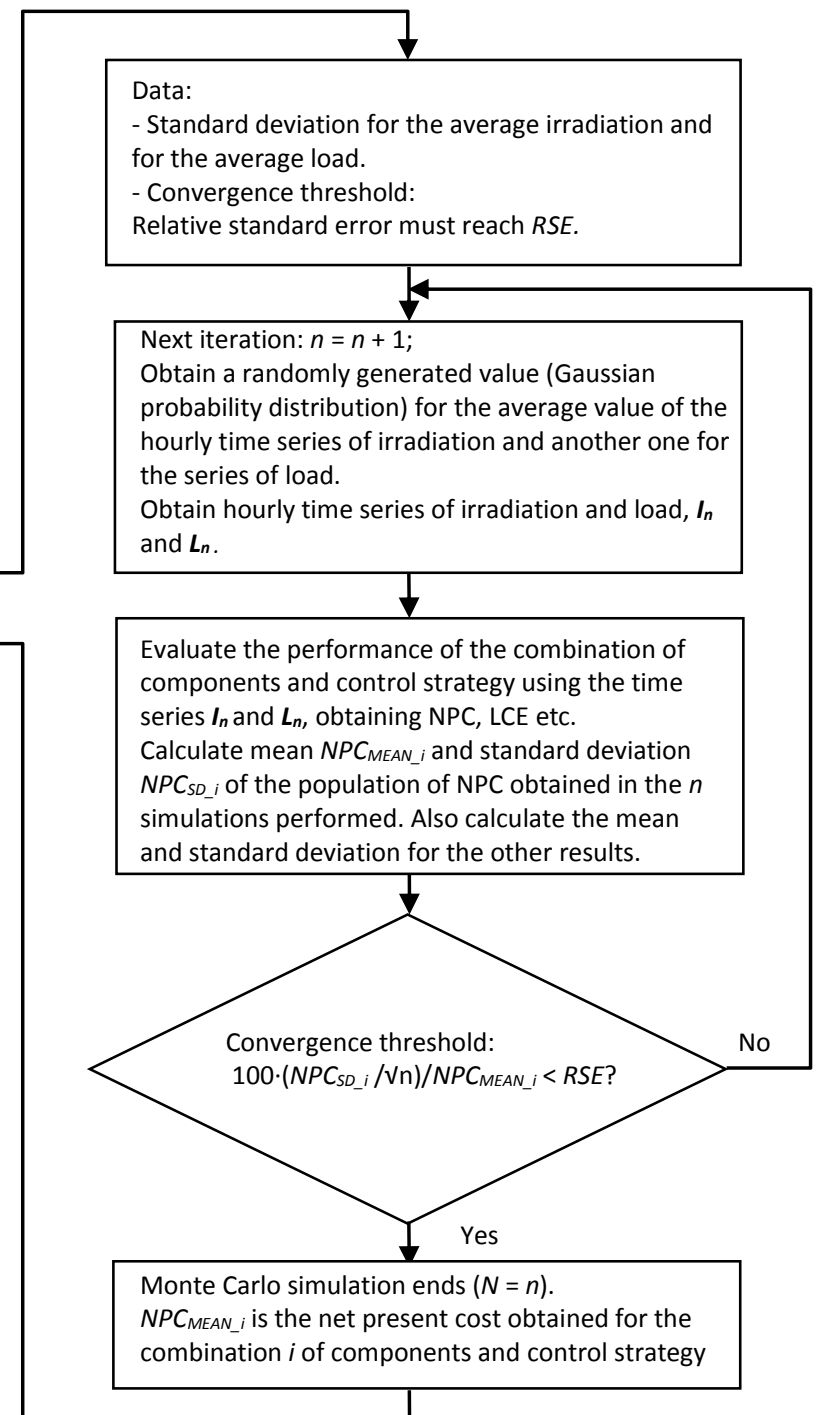

Fig. 2. Optimisation flowchart 


\section{Electrical supply of an off-grid hospital in Congo.}

The methodology shown in section 2 has been applied in the optimisation of the electrical supply of an off-grid hospital located in Kalonge (Democratic Republic of the Congo, Sud Kivu, near Rwanda, latitude $2.33^{\circ} \mathrm{S}$, longitude $28.75^{\circ} \mathrm{E}$ ). There is no other hospital within 150 $\mathrm{km}$; the nearest one is between 3 and 6 hours away, depending on road conditions. The electricity is currently supplied by a diesel generator during the day (which also charges the batteries) and batteries during night hours.

The work performed in this hospital by NGOs, such as Doctors Without Borders, is of great help to the population of the area, so it is of great interest to improve the conditions of power supply to the hospital.

We propose the PV-diesel-battery system shown in Fig. 3 to improve the power supply to the hospital. The system is currently composed of a diesel generator and batteries. Adding a PV generator will allow major flexibility and reliability. The load can be fed directly from the diesel generator or from the batteries (using an inverter). The charger function allows battery charging with the genset.

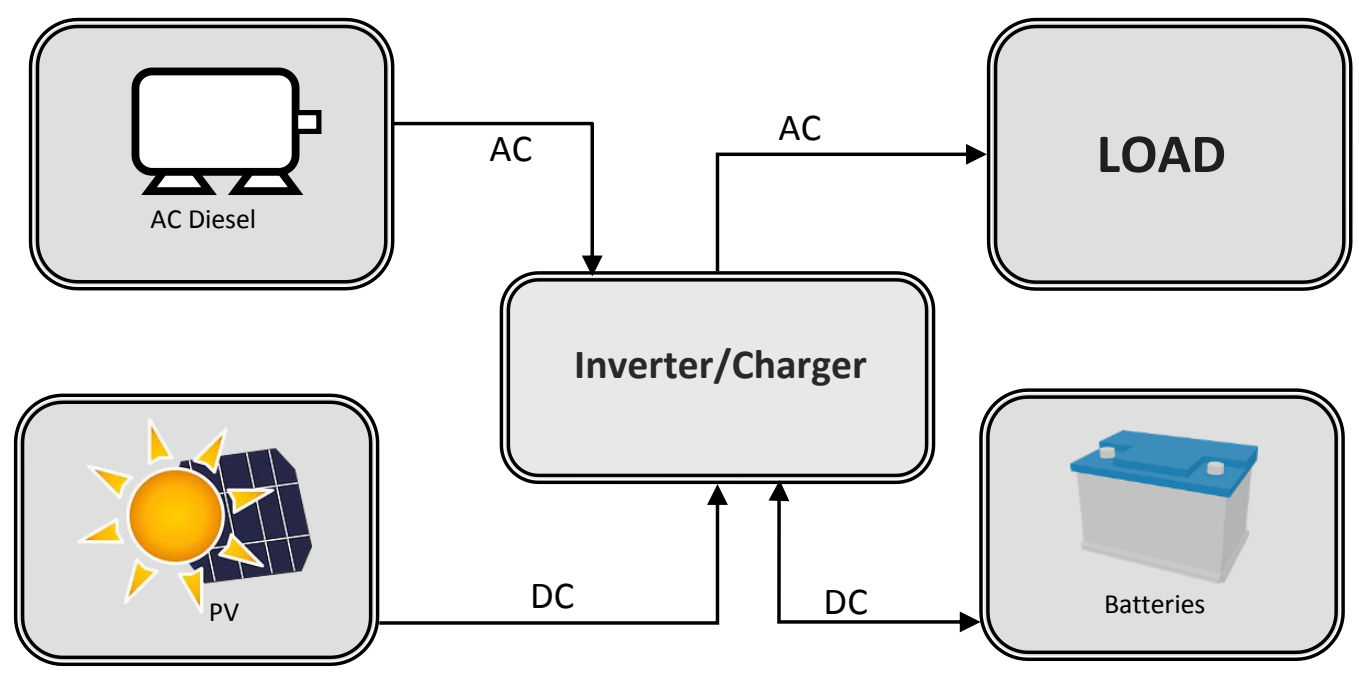

Fig. 3. Proposed PV-diesel-battery system

This system will be described in detail in the following subsections. Later, in section 4, the performances of the present system (diesel-battery), a proposed PV-diesel-battery system and an optimised PV-diesel-battery system (using the methodology of section 2) are shown. 


\subsection{Load}

The load is between 1.8 and $2.8 \mathrm{~kW}$ for the hours of a typical full working day. However, there are some days where the load is much lower (due to few patients) or even close to zero. We have modelled it as 5 full working days followed by 2 days with no load. Fig. 4 shows the hourly load of 14 days. The power factor of the load is 0.9 . The average daily load during the year is $36.23 \mathrm{kWh} /$ day, and the total load of the year is $13,224 \mathrm{kWh} / \mathrm{yr}$. We will consider a standard deviation for the average daily load Gaussian distribution curve of $5 \mathrm{kWh} /$ day.

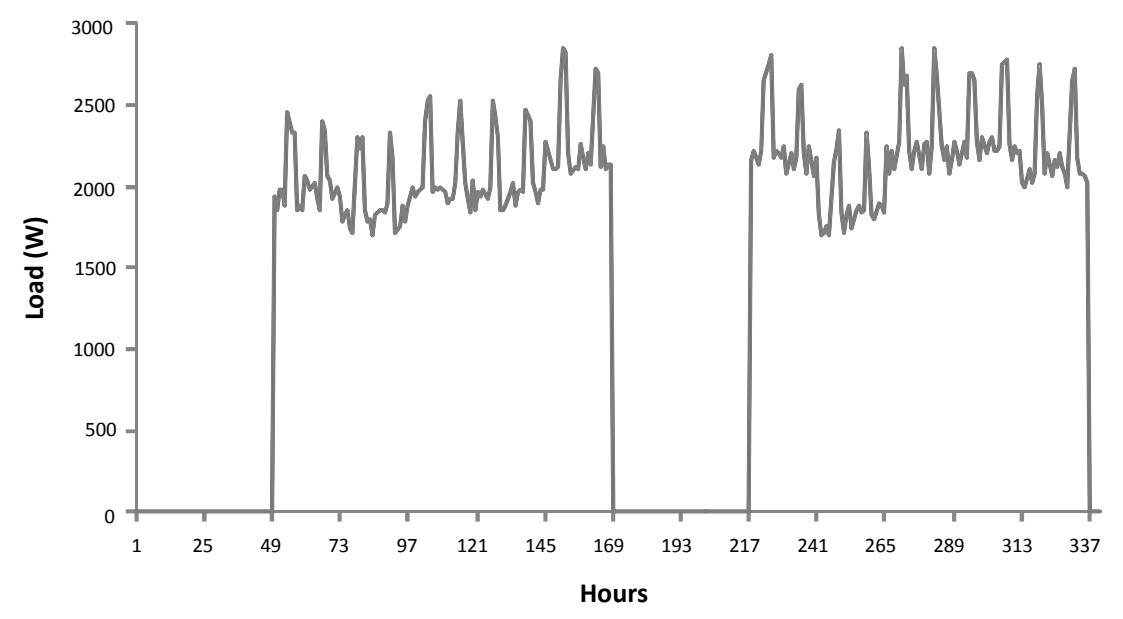

Fig. 4. Load (W)

\subsection{Diesel generator}

The rated continuous output power of the current genset is $8.5 \mathrm{kVA}$, its acquisition cost is 8,000 $€$ and its operation and maintenance $(\mathrm{O} \& \mathrm{M})$ cost is $0.14 € / \mathrm{h}$. Its expected lifespan is about $15,000 \mathrm{~h}$ in the conditions of the Congo. The fuel (gas-oil) price is $1.3 € / 1$, and we are considering only a $2 \%$ annual inflation rate (it is probable that it will be higher; however, we use a conservative value, as we are going to compare later with a hybrid system which includes a photovoltaic generator). Fuel consumption, FC (1/h), is modelled as dependant on the output power, $P(\mathrm{~kW})$, with Eq. (2).

$$
F C=A \cdot P+B \cdot P_{N}
$$

where $P_{\mathrm{N}}(\mathrm{kW})$ is the nominal output power, and $A$ and $B$ are the coefficients of the consumption curve. The values suggested by Skarstein and Ullen [34] have been used here: $\mathrm{A}=$ $0.246 \mathrm{l} / \mathrm{kWh}$ and $\mathrm{B}=0.08145 \mathrm{l} / \mathrm{kWh}$. The minimum output power recommended by the manufacturer is usually $30 \%$ of the rated power, the value used in the simulations. The genset is not available at night, from 10 p.m. to 4 a.m. 


\subsection{Batteries}

There are three groups of four solar AGM lead-acid batteries of $200 \mathrm{Ah}\left(\mathrm{C}_{10}\right), 12 \mathrm{~V}$ (each battery of $2.4 \mathrm{kWh}$ nominal capacity). Therefore, the total capacity of the batteries is equal to $28.8 \mathrm{kWh}\left(C_{b a t}\right)$. Each battery bank supplies the load of different services when the diesel genset is not ready to run. The four batteries of each group are in parallel. The minimum state of charge $\left(S O C_{\min }\right)$ recommended by the manufacturer for all of them is $40 \%$. Thus, the total available storage capacity is equal to $17.8 \mathrm{kWh}(28.8 \cdot 0.6)$, and the expected self-discharge coefficient is $5 \%$ monthly. The roundtrip efficiency is $80 \%$. We have considered 12 years of floating life. Fig. 5 (AGM curve) shows the curve of cycles to failure vs. depth of discharge, and the average number of full equivalent cycles to failure is 605 .

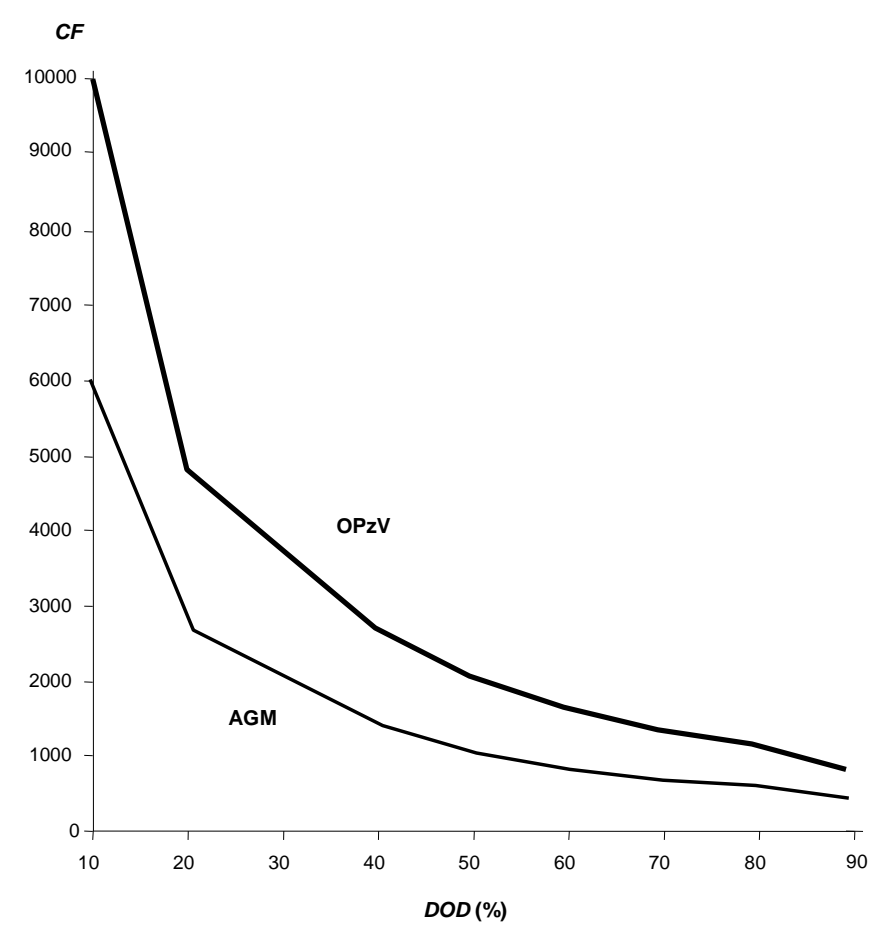

Fig. 5. Cycles to failure (CF) vs. depth of discharge (DOD)

The battery model considered is the weighted Ah-throughput model proposed by Schiffer et al. [24]. The acquisition cost of each battery is $230 €$ (i.e., $95.8 € / \mathrm{kWh}$ ), and its O\&M cost is expected to be $1 \%$ of the acquisition cost $(2.3 € /$ yr. for each battery) plus a fixed value of 50 $€ /$ year, for a total of $77.6 € / \mathrm{yr}$.

\subsection{Inverter-chargers (bi-directional converter)}

There are 3 inverter-chargers, one for each group of batteries. The output continuous power of each unit is 1,100 VA, and its acquisition cost is 2,000 $€$. The maximum continuous direct current for each unit is $40 \mathrm{~A}$. Nominal DC voltage is $12 \mathrm{~V}$. The diesel generator's inverter- 
chargers charge each group of batteries. When the generator is not allowed to work (at night or if it is unavailable), the three battery banks supply the load by means of the three inverterchargers. The lifespan considered for the inverter-chargers is 15 years, the efficiency considered is $94 \%$ for the charger and the inverter efficiency is considered as dependant on the output power (Fig. 6). The battery charge includes four stages (bulk, absorption, float and equalisation). Each inverter-charger includes a built-in solar charge controller (maximum input current $30 \mathrm{~A}$ ), but it does not include maximum power point tracking (MPPT).

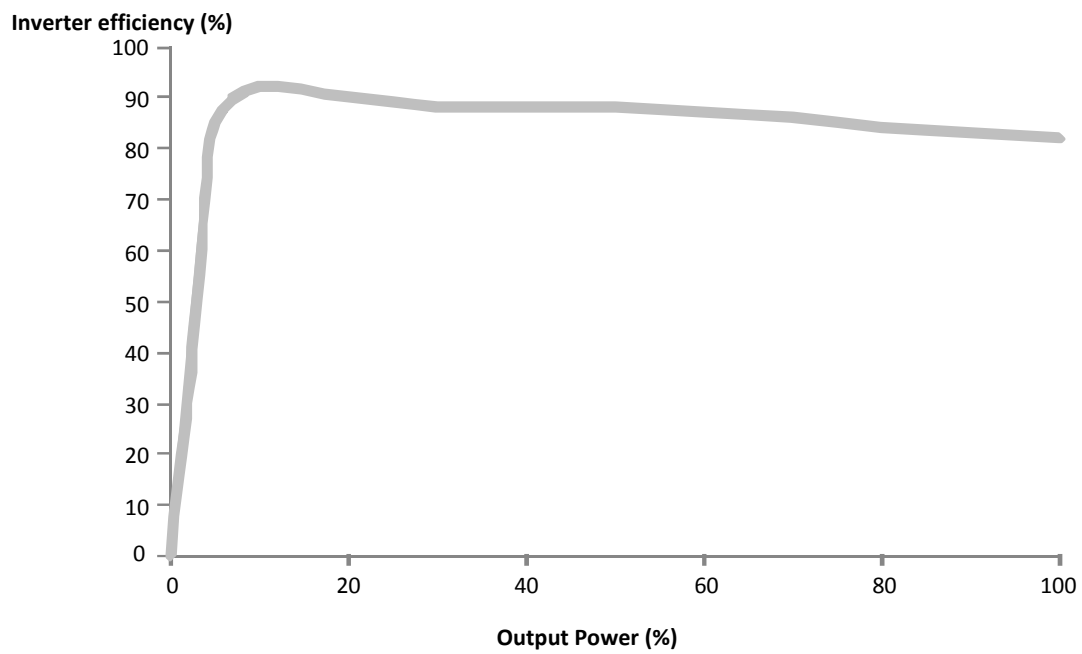

Fig. 6. Inverter efficiency

\subsection{Control strategy}

During daytime, energy is supplied by the diesel generator, which also charges the batteries. The batteries are used in order to ensure the basic supply of energy when the generator is unavailable (night hours) or under maintenance. The strategy used in the present system is the "cycle-charging strategy" [27]: when the generator must run, it will run at its rated power, so the extra power will charge the batteries.

\subsection{Other data}

The lifespan considered for the system is 25 years (to compare later with the hybrid PV-dieselbattery proposed systems). The annual nominal interest and general inflation rates are $4 \%$ and $2 \%$, respectively. These rates are expected in European developed countries, as the components are manufactured there or their price is fixed there. These rates are applied to calculate the cost of replacement for the elements of the system when they reach the end of their lifespan, the remaining value of the elements (at the end of the lifetime of the system) and the total NPC of the system. 
An installation cost of $300 €+2 \%$ of total initial cost has been considered. A loan of $80 \%$ of initial cost has been considered as a loan with an interest of $10 \%$ annually for 10 years.

\section{Simulation and optimisation results}

In this section, the present system (diesel-battery) is simulated in a stochastic approach using Monte Carlo simulation (no optimisation is performed, as we just want to know the performance of the present system). Then the same is done for a proposed system composed of the present system plus a PV generator. Finally, the optimisation of a PV-diesel-battery system is performed using the methodology shown in section 2 .

\subsection{Present diesel-battery system}

Monte Carlo simulation has been done to evaluate the performance of the present system. The convergence threshold of the Monte Carlo simulation is that the relative standard error (considering the results of NPC) must be lower than $R S E=0.2 \%$, with a minimum of 2,000 samples.

The number of samples necessary to obtain a relative standard error lower than $0.2 \%$ has been lower than the minimum, so $\mathrm{N}=2,000$. A computer with $4 \mathrm{~GB} \mathrm{RAM}$ and $2.4 \mathrm{GHz}$ ran the necessary 130 seconds to perform the analysis (around 15 samples per second).

The results of the Monte Carlo simulation are the following (mean of each variable):

$N P C$ is $281,940 €$, and the $L C E$ is equal to $0.87 € / \mathrm{kWh}$. During one year, the diesel generator runs $4,680 \mathrm{~h}$ (so its expected lifespan is $15,000 / 4,680=3.2$ years), and it supplies $15,507 \mathrm{kWh}$ (consuming 7,054 litres of gas-oil with emissions of 26,034 $\mathrm{kg}$ of $\mathrm{CO}_{2}$ ). From this energy, 4,217 $\mathrm{kWh}$ are used to charge the batteries, and the rest is used to supply the load directly; the batteries are charged over 4,518 $\mathrm{h}$ and discharged over 1,555 $\mathrm{h}$.

The batteries expected lifespan, calculated using the weighted Ah-throughput model proposed by Schiffer et al. [24], is 2.91 years.

We have also repeated the simulations using classical models to see the difference in the batteries expected lifespan: considering the average number of full equivalent cycles, the battery lifetime would be estimated at 4.27 years; using the rainflow cycle counting model, it would be 4.24 years. These values are much more optimistic and differ significantly from reality. 


\section{Random data:}

Load: mean $36.11 \mathrm{kWh} /$ day. Std. Dev.: 5.07

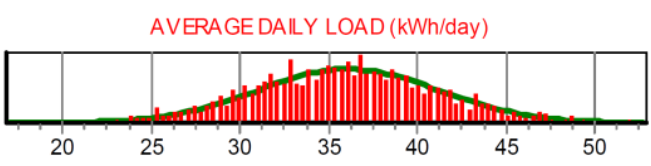

Results:

Total Cost (NPC): mean $281940 €$. Std. Dev.: 21223

Lev. cost of energy: mean $0.87 € /$ kWh. Std. Dev.: 0.082
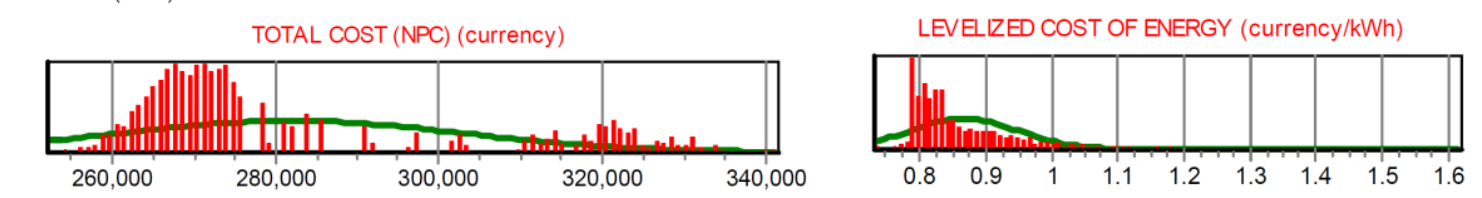

CO2 Emissions: mean 26034.23 kgCO2/yr. Std. Dev.: 1621.49

CO2 EMISSIONS (kg/yr)

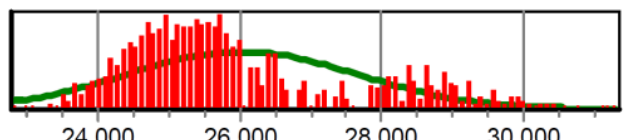

Batteries lifetime: mean $2.91 \mathrm{yr}$. Std. Dev.: 1.17

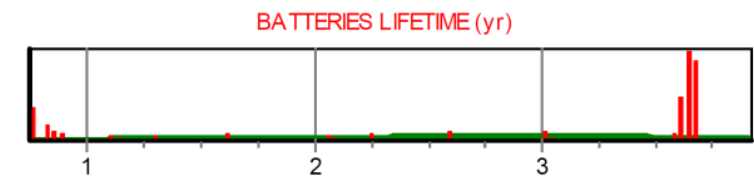

AC gen. fuel: mean 7054.24 litre/yr. Std. Dev.: 314.25 AC GENERA TOR FUEL CONSUMPTION (ud/yr)

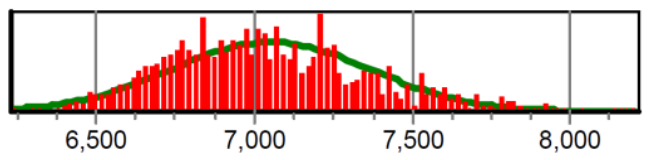

Energy of AC generator: mean 15507 kWh/yr. Std. Dev.: 1276

ENERGY GENERATED BY AC GENERATOR (kWh/yr)

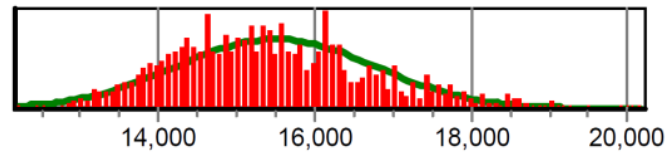

Fig. 7. Main results of current diesel-battery system

Fig. 7 shows the distribution curves of data (load) and main results (NPC, LCE, $\mathrm{CO}_{2}$ emissions, batteries expected lifetime, diesel generator fuel consumption and energy supplied). In red, the probability distribution obtained can be seen, and in green, the normal curve which best fits is shown. In this case, we can see that NPC, $\mathrm{LCE}, \mathrm{CO}_{2}$ emissions and batteries expected lifetime probability distributions differ greatly from a normal distribution curve; however, diesel generator fuel consumption and energy are similar to a Gaussian curve. In addition, LCE has lower dispersion than NPC, as LCE is obtained by dividing NPC by the total energy load consumed during the 25 years. Samples with high loads imply very high NPC values (high fuel consumption and low battery lifetimes); however, as the LCE is calculated as NPC/load/25, although the NPC is very high, the load is also high, so the LCE has a lower dispersion.

Fig. 8 shows the simulation for the present diesel-battery system between January 23 and 29 in the $1^{\text {st }}$ year. 


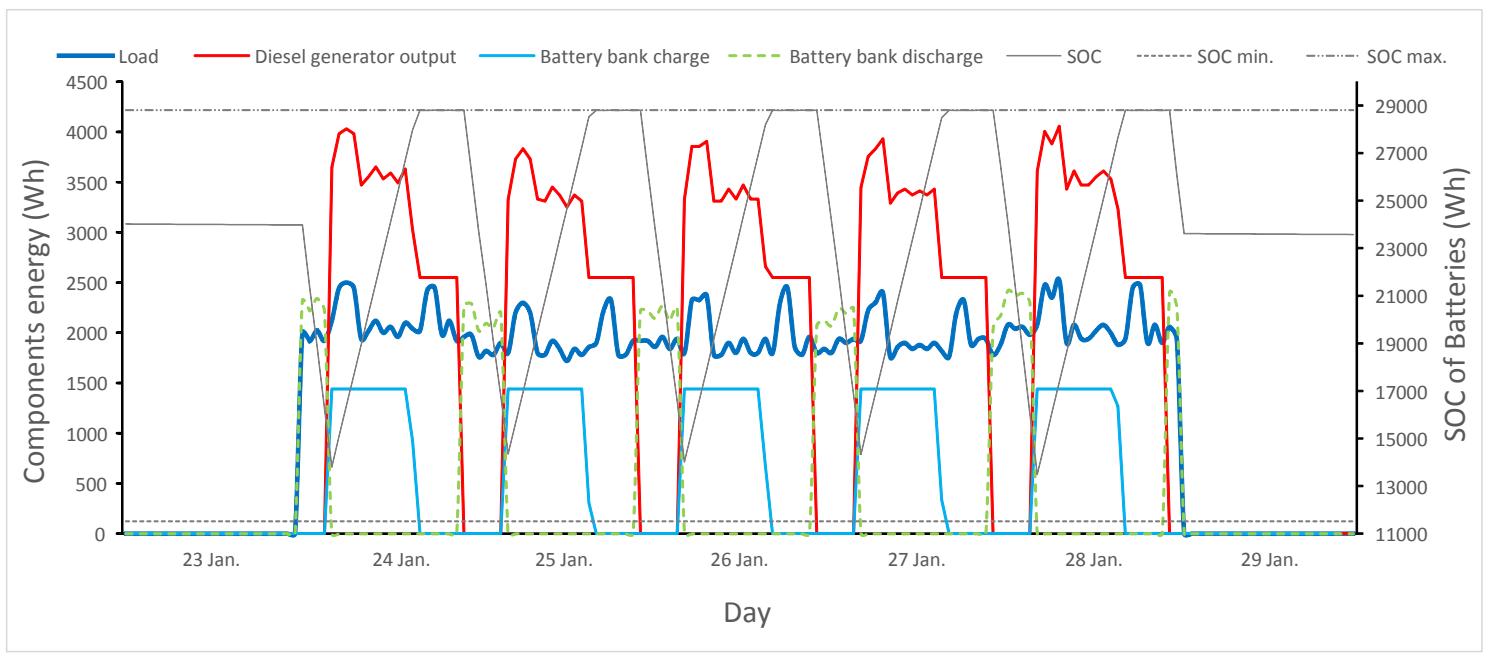

Fig. 8. Simulation of 7 days for the current diesel-battery system

\subsection{PV-diesel-battery (original system plus PV generator)}

We propose modifying the current diesel-battery system by adding a PV generator for each group of batteries. In this first study case, without applying any optimisation technique, a PV generator has been added to the current diesel-battery system.

The PV generator will be composed of mono-Si PV panels of $P_{P V}=100 \mathrm{Wp}$, shortcut current $I_{S C}$ $=6.79 \mathrm{~A}$, nominal voltage $V_{\text {nom }}=12 \mathrm{~V}$, open-circuit voltage $21 \mathrm{~V}$, lifespan 25 years, acquisition cost $150 €$ (including support structure), O\&M cost $2 € /$ yr. (plus $40 € /$ year for the whole PV system), NOCT $46^{\circ}$ and power temperature coefficient $-0.45 \% /{ }^{\circ} \mathrm{C}$. As the maximum DC for the $\mathrm{PV}$ generator connected at each inverter-charger is $30 \mathrm{~A}$, the number of panels in parallel cannot be higher than $30 / 6.79=4.41$, or 4 panels in parallel. So for each inverter-charger, a PV generator of $400 \mathrm{Wp}$ will be installed (total 1,200 Wp).

The panels have an inclination of $15^{\circ}$ (the optimal for this location would be $0^{\circ}$, but a minimum slope is set to avoid dirtiness), $180^{\circ}$ azimuth (north orientation). NASA's webpage has given the irradiation and temperature of the location [35]. We have obtained the average hourly time series of the irradiation using the Graham and Holland method, which gives the hourly irradiation over the tilted surface of the PV panels [36]. The ground reflectance considered is 0.2 (typical). The average total annual irradiation over the PV panels is $5.01 \mathrm{kWh} / \mathrm{m}^{2} /$ day. There is no data for that location for the standard deviation of the average irradiation. However, in [37], data on locations at several hundreds of km from the location, in Tanzania and Congo, can be found, with values around $0.2 \mathrm{kWh} / \mathrm{m}^{2} /$ day, which is the value we will use; in [38], values of around $0.13 \mathrm{kWh} / \mathrm{m}^{2} /$ day are obtained for several locations in Spain and Algeria. As the inverter-chargers do not include an MPPT system, the output current will be proportional to the shortcut current [10], so the output power from each PV panel will be $P_{P V}(\mathrm{~W})=G(\mathrm{~kW}) / 1 \mathrm{~kW}$. 
$I_{S C}(\mathrm{~A}) \cdot V_{\text {nom }}(\mathrm{V}) \cdot P R$, where $G$ is the irradiance over the surface of the PV panel and $P R$ is the performance ratio, considered here to be 0.83 (due to dirtiness, losses in cables and other problems).

The convergence threshold of the Monte Carlo simulation is that the relative standard error must be lower than $0.2 \%$, with a minimum of 2,000 samples. In this case, $\mathrm{N}=2,000$ samples have been simulated.

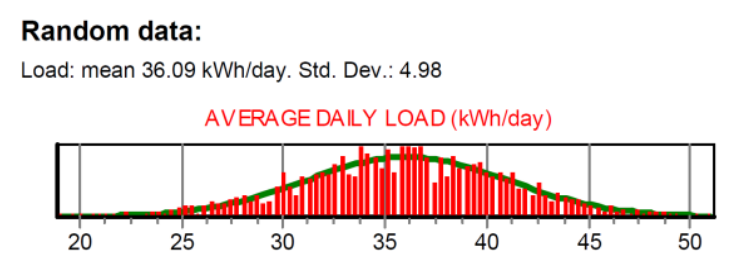

\section{Results:}

Total Cost (NPC): mean $269216 €$. Std. Dev.: 6911.1

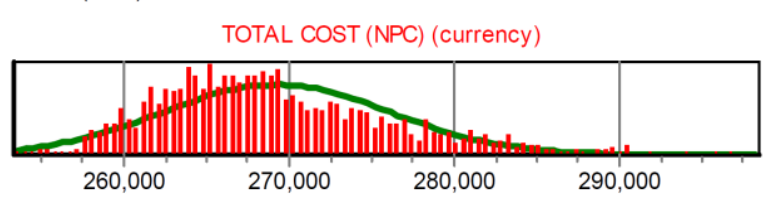

Irradiation: mean $5.03 \mathrm{kWh} / \mathrm{m} 2 /$ day. Std. Dev.: 0.2

AVERAGEDAILY IRRADIATION (kWh/m2/day)

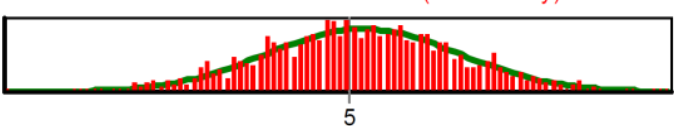

Lev. cost of energy: mean $0.83 € / \mathrm{kWh}$. Std. Dev.: 0.102 LEVELIZED COST OF ENERGY (currency/kWh)

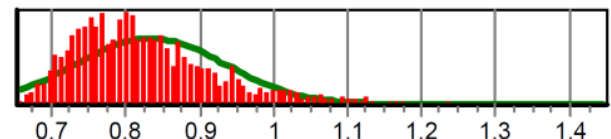

CO2 Emissions: mean 24837.88 kgCO2/yr. Std. Dev.: 909.87 Batteries lifetime: mean 4.57 yr. Std. Dev.: 0.23

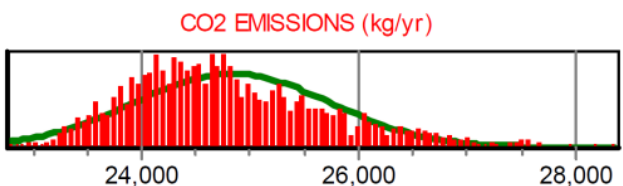

AC gen. fuel: mean 6823.29 litre/yr. Std. Dev.: 254.67 AC GENERATOR FUEL CONSUMPTION (ud/yr)

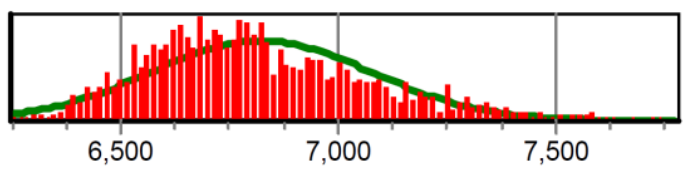

Energy of AC generator: mean $14570 \mathrm{kWh} / \mathrm{yr}$. Std. Dev.: 1033.9

ENERGY GENERATED BY AC GENERATOR (kWh/yr)

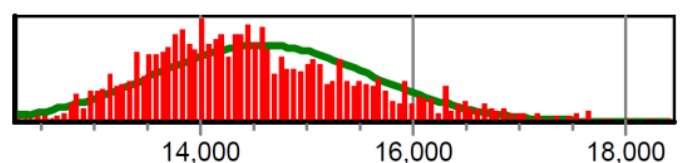

Fig. 9. Main results of PV-diesel-battery system (original system + PV)

Fig. 9 shows the results of the original system plus a 1,200 Wp PV generator. The reduction in the mean of $L C E$ is quite low ( 0.83 vs. $0.87 € / \mathrm{kWh}$ of the original system). However, the expected battery lifetime is much higher (mean of 4.57 vs. 2.91 years), and the dispersion is much lower (the standard deviation being 0.23 vs. 1.17 years).

\subsection{PV-diesel-battery optimised system}

A PV-diesel-battery system (using the actual $8.5 \mathrm{kVA}$ diesel generator) has been optimised, comparing different combinations of systems and obtaining the one with the lowest NPC mean.

Next, the elements considered in the optimisation and the results are described. 


\subsubsection{Inverter-charger}

We have considered two new inverter-chargers. An inverter-charger composed of two units in parallel of a Xantrex XW6048-230-50 (6000 W, 131 A DC) + solar charger XW-MPPT60-150 (type A) and an inverter-charger composed of four units in parallel of the same Xantrex XW6048-230-50 (type B). The main characteristics of both types are detailed in Table 1.

Table 1. Inverter-chargers

\begin{tabular}{lcc}
\hline Type & A & B \\
\hline Acq. cost $(€)$ & 8,000 & 16,000 \\
Max. PV power $(\mathrm{Wp})$ & 7,000 & 14,000 \\
Expected lifespan $(\mathrm{yr})$ & 15 & 15 \\
Nominal DC voltage $(\mathrm{V})$ & 48 & 48 \\
Efficiency & Same as actual system & Same as actual system \\
\hline
\end{tabular}

\subsubsection{PV panels}

We consider the same type of PV panels of $100 \mathrm{Wp}$ and $12 \mathrm{~V}$. As the PV generator of each solar charger is limited to 3,500 Wp, a maximum of eight groups of four panels of $100 \mathrm{Wp}$ in parallel are allowed for each solar charger. For inverter-charger A, with two solar chargers, the maximum is 16 groups of four panels in parallel. For inverter-charger B, with four solar chargers, the maximum is 32 groups of four panels in parallel.

The software will try 33 combinations of PV generators (between 0 and 32 groups of four panels in parallel).

\subsubsection{Batteries}

We have considered $2 \mathrm{~V} \mathrm{OPzV}$ batteries, so 24 batteries in serial will compose the battery bank. The software will try combinations of eight different batteries (Table 2), between 206 and 2020 Ah $\left(\mathrm{C}_{10}\right)$. The acquisition cost of the batteries is shown in Table 2 , around $250 € / \mathrm{kWh}$. The minimum SOC recommended by the manufacturer is $20 \%$, the self-discharge coefficient is $3 \%$ monthly and the roundtrip efficiency is $85 \%$. The curve of cycles to failure vs. DOD is shown in Fig. $5(\mathrm{OPzV})$, and the number of full equivalent cycles to failure is 1,174 . The manufacturer datasheet shows 18 years of floating lifetime. A fixed cost of $50 € / \mathrm{yr}$. of O\&M has been considered for the battery bank.

Table 2. OPzV $2 \mathrm{~V}$ batteries acquisition cost

\begin{tabular}{lcccccccc}
\hline $\mathrm{C}_{10}(\mathrm{Ah})$ & 206 & 258 & 309 & 361 & 505 & 1,030 & 1,515 & 2,020 \\
Acq. cost $(€)$ & 166 & 192 & 218 & 235 & 301 & 525 & 700 & 991 \\
\hline
\end{tabular}




\subsubsection{Control strategies}

Two possible control strategies have been considered: load following and cycle charging [27].

Load following strategy: In this strategy, when energy from the PV generator is not enough to meet the whole load, the rest of the energy is covered by the battery bank. If the batteries cannot cope with the demand, the diesel generator will run to cover the rest of the load.

Cycle charging strategy: When the generator must run because the load cannot be met by the batteries, it will run at its rated power, so the extra power will charge the batteries.

\subsubsection{Results}

We have evaluated a total of 33 combinations of PV generator $x 8$ combinations of battery bank $\mathrm{x} 2$ combinations of control strategies $=528$ combinations of components and control strategies. Combinations with PV power lower than 7,000 Wp use inverter type A, and combinations with PV higher than that value use inverter type B.

Considering that Monte Carlo simulation must consider around 2,000 samples for each combination, the number of total simulations would be around 2 million. The optimisation has taken around 22 hours, evaluating all the combinations of components and control strategies.

The optimal hybrid system found is a PV generator of $4 \times 31 \mathrm{PV}$ panels of $12 \mathrm{~V}, 100 \mathrm{Wp}$ (total $12.4 \mathrm{kWp}$ ), the original diesel generator of $8.5 \mathrm{kVA}$, a battery bank of 24 batteries in serial of 2 $\mathrm{V}, 1,030 \mathrm{Ah}$ (total $49.44 \mathrm{kWh}$ ) and the set of four inverter-chargers in parallel using the loadfollowing strategy. Fig. 10 shows the main results of the optimal system.

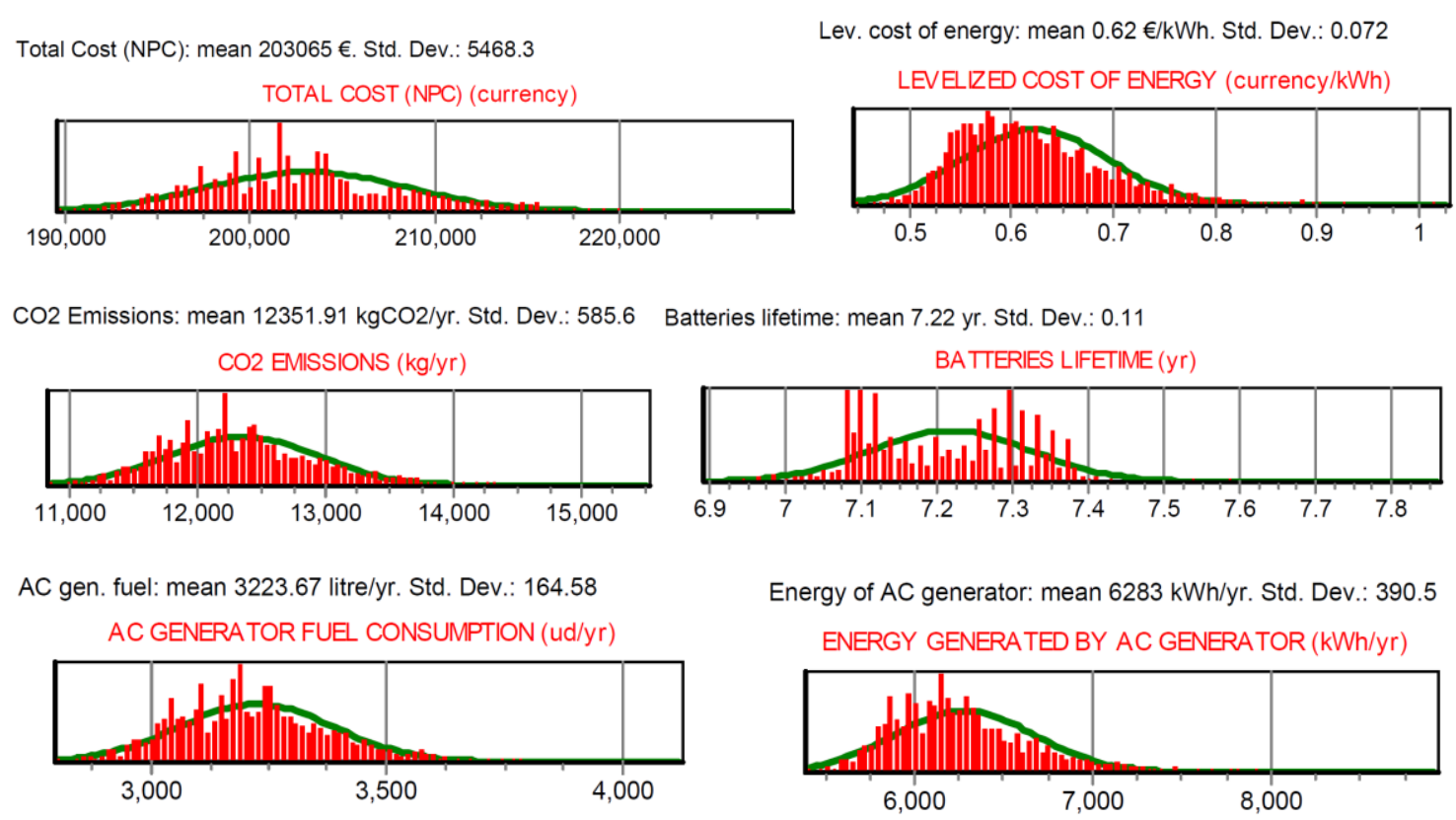

Fig. 10. Main results of the optimal PV-diesel-battery system 
Table 3 summarises the results of the optimal hybrid system, and the simulation of 7 consecutive days is shown in Fig. 11. A more detailed simulation for a day (January 25) is shown in Fig. 12. The expected mean of LCE of the optimal hybrid system is $0.62 € / \mathrm{kWh}, 28 \%$ lower than the current diesel-battery system. The diesel fuel consumption is reduced by $54 \%$. We conclude that this optimal hybrid system is worth installing, as the cost of the energy will be much lower than for the current system, even considering a very low interest rate for the fuel price ( $2 \%$ annual; if this interest rate were higher, the difference in LCE would be higher).

Table 3. Results of the different cases

\begin{tabular}{|c|c|c|c|c|c|c|}
\hline & \multicolumn{2}{|c|}{$\begin{array}{l}\text { 1. Diesel-battery } \\
\text { (current system) }\end{array}$} & \multicolumn{2}{|c|}{$\begin{array}{c}\text { 2. Diesel-battery (current } \\
\text { system) plus PV gen. of } 1200 \\
\text { Wp }\end{array}$} & \multicolumn{2}{|c|}{$\begin{array}{l}\text { 3. PV-diesel-battery } \\
\text { optimal system }\end{array}$} \\
\hline Diesel rated power (kVA) & \multicolumn{2}{|c|}{8.5} & \multicolumn{2}{|c|}{8.5} & \multicolumn{2}{|c|}{8.5} \\
\hline $\begin{array}{l}\text { Batteries: } \\
\text { Nominal capacity (kWh) } \\
\text { Type }\end{array}$ & & & & & & \\
\hline $\begin{array}{l}\text { Inverter-charger: } \\
\text { Rated output power }(\mathrm{kW}) \\
\text { Max. PV peak power }(\mathrm{kWp})\end{array}$ & & & & & & \\
\hline PV peak power $(\mathrm{kWp})$ & \multicolumn{2}{|c|}{0} & \multicolumn{2}{|c|}{1.2} & \multicolumn{2}{|c|}{12.4} \\
\hline Control strategy & \multicolumn{2}{|c|}{ Cycle charging } & \multicolumn{2}{|c|}{ Cycle charging } & \multicolumn{2}{|c|}{ Load following } \\
\hline RESULTS: & Mean & $\begin{array}{l}\text { Std. } \\
\text { Dev. }\end{array}$ & Mean & $\begin{array}{l}\text { Std. } \\
\text { Dev. }\end{array}$ & Mean & Std. Dev. \\
\hline NPC $(€)$ & 281,940 & 21,223 & 269,216 & 6,911 & 203,065 & 5,468 \\
\hline $\mathrm{LCE}(€ / \mathrm{kWh})$ & 0.87 & 0.082 & 0.83 & 0.102 & 0.62 & 0.072 \\
\hline Diesel runs (h/yr.) & 4,680 & 0 & 4,680 & 0 & 2,424 & 101 \\
\hline Diesel lifespan (yr.) & 3.2 & 0 & 3.2 & 0 & 6.2 & 0.25 \\
\hline Diesel supplies (kWh/yr.) & 15,507 & 1,276 & 14,570 & 1,034 & 6,283 & 390 \\
\hline Diesel consumption (litres/yr.) & 7,054 & 314 & 6,823 & 254 & 3,224 & 164 \\
\hline $\mathrm{CO}_{2}$ emissions & 26,034 & 1,621 & 24,838 & 910 & 12,352 & 585 \\
\hline $\begin{array}{l}\text { Energy cycled by batteries } \\
\text { (kWh/yr.) }\end{array}$ & 4,217 & 535 & 4,071 & 552 & 3,798 & 494 \\
\hline Batteries lifespan (yr.) & 2.91 & 1.17 & 4.57 & 0.23 & 7.22 & 0.11 \\
\hline PV supplies (kWh/yr.) & - & - & 1,496 & 60 & 18,243 & 683 \\
\hline
\end{tabular}




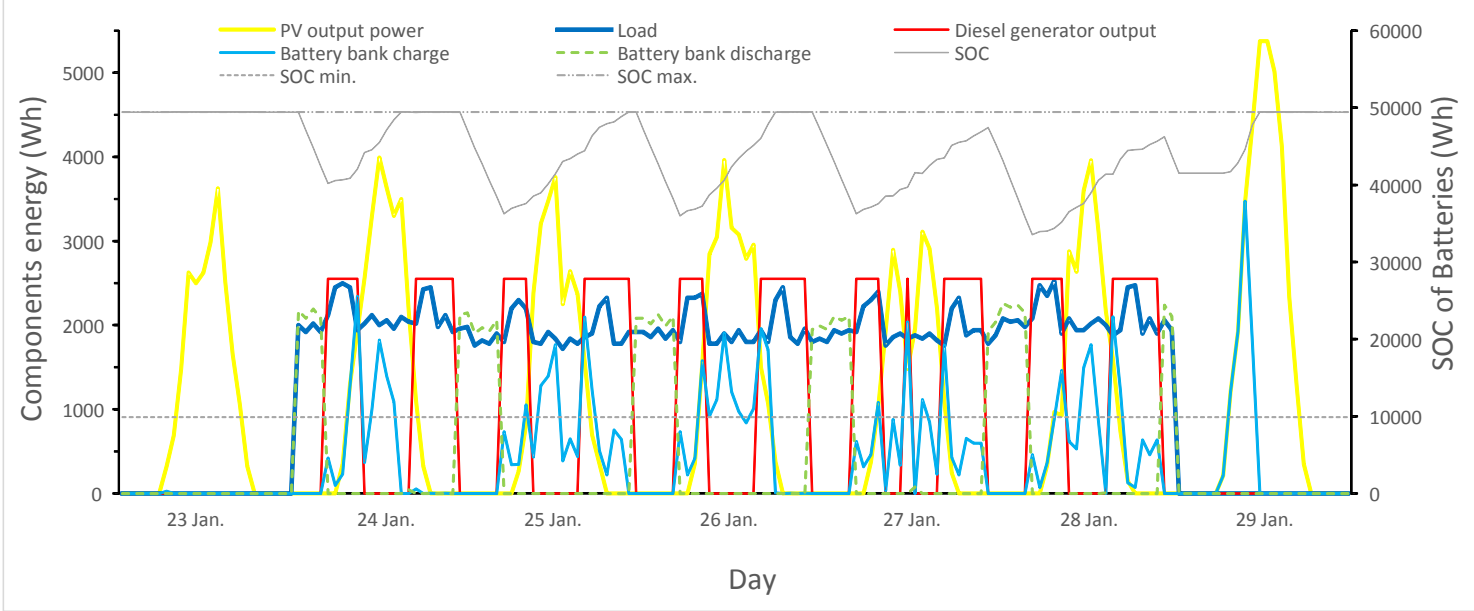

Fig. 11. Simulation of 7 days for the optimal PV-diesel-battery system

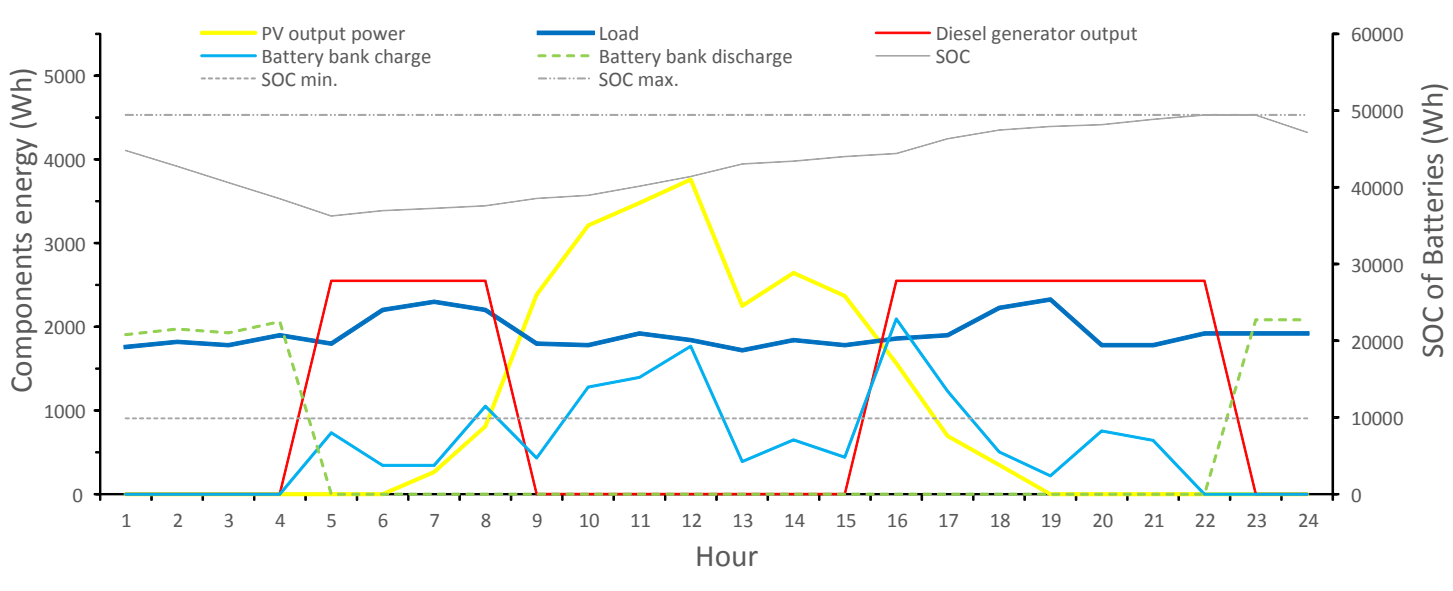

Fig. 12. Simulation of 24 hours for the optimal PV-diesel-battery system

After the optimisation of the energy production, the inclusion of a BSN with M2M could be of great interest in order to improve communications from the hospital. It would make it possible to send medical information from patients to other hospitals with more resources and medical specialists. The consumption of BSN devices is in the order of $\mathrm{mW}$, as the device with more consumption is the M2M gateway that links with the outside. This consumption can be supplied without problems, using the renewable energy system proposed in this paper. 
Taking into account the hospital's location and its orographic conditions, a potential difficulty in improving its telecommunications may be obtaining an Internet connection. Perhaps the best solution would be to install a very-small-aperture terminal (VSAT) antenna on the roof to obtain a satellite connection, but the initial investment and monthly cost would be prohibitive.

A more feasible solution would be to use the VSAT communications installed in the office of Doctors Without Borders [39], located $1.5 \mathrm{~km}$ from the hospital. If a WIMAX connection is installed from the hospital to this office, then it would be possible to use the VSAT service at the hospital. Although the connection speed is not very high (about $60 \mathrm{kB} / \mathrm{s}$ ), it could be used to transmit noncritical patient data.

In summary, with an initial investment in M2M devices, an M2M gateway and WIMAX connection could begin transmitting certain vital signs of patients to other hospitals where they could be properly analysed. The process of adaptation to M2M technology is very simple because it relies on wearables (a BSN). If the experiment is successful and economically viable, it could increase energy production and provide the hospital with a satellite connection (Fig. 12). Obviously, this would increase energy consumption, but the PV-diesel-battery system ensures a supply of all the telecommunications system energy demands as well as scalability if the load must be increased.

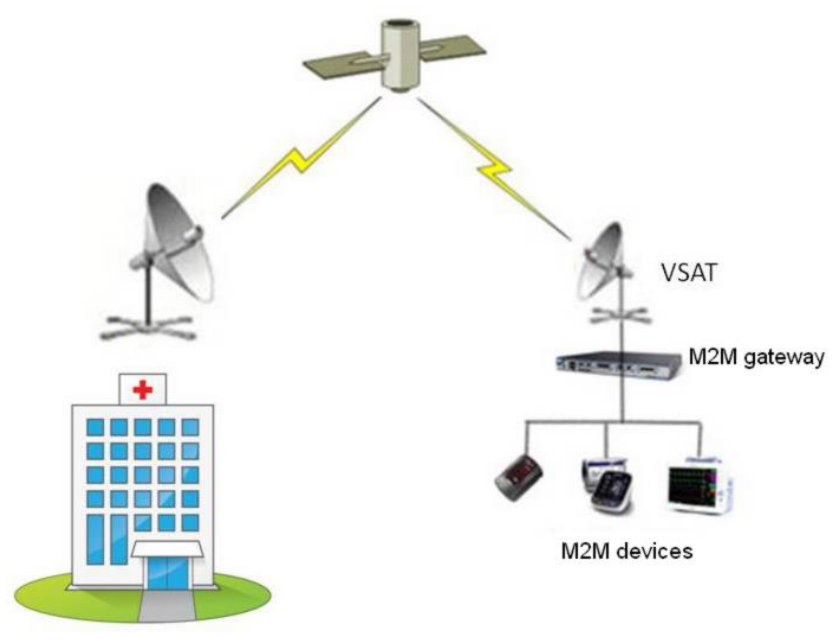

Fig 12. Proposed telecommunications system 


\section{Conclusions and future works}

In this paper, a new methodology for the optimisation of off-grid hybrid systems (photovoltaicdiesel-battery systems) is shown. A Monte Carlo simulation is applied to consider the uncertainties of irradiation and load in the optimisation process. Previous works which use the stochastic approach use classical models for the batteries, obtaining values for the batteries lifetime which could be much higher than in reality, so the expected cost of the system is not correctly calculated. In this work, an advanced weighted Ah-throughput model for the lead-acid batteries is included in the model, obtaining results of batteries expected lifespan much closer to reality than those obtained using classical models of batteries, thus obtaining a much more accurate net present cost and levelised cost of energy (which includes the cost of batteries replacement during the system lifetime).

The probabilistic approach has been applied to the optimisation of the electricity supply to an off-grid hospital in Kalonge, Democratic Republic of the Congo, which currently uses a dieselbattery system. The optimisation of a PV-diesel-battery system is performed. The results show that the application of renewable energy systems in this Kalonge hospital, without the help of an optimisation tool, can lead to economically undesirable results. However, with the optimisation tool, cost reduction can be very significant (28\%) and reduction in fossil fuel consumption even more so (54\%), also reducing the pollutant emissions. Analysing these results and conducting further studies to improve the reliability of the supply both seem advisable, considering how critical these resources are and that in other hospitals, consumption is greater.

Furthermore, we have proposed possible improvements to the hospital's telecommunications.

Doctors Without Borders carries out its activities in other hospitals in Africa, such as in Batangafo and Kabo (Central African Republic), Shabunda (Congo), Deghabur (Ethiopia) and Madaoua (Niger). The results shown in this article could be extrapolated to others, offering potential energy- and cost-efficient improvements.

\section{Acknowledgements}

The authors would like to thank Doctors Without Borders (Médicos Sin Fronteras, MSF in Spanish) and especially to Iñaki Goicolea, MIO Energy, Cold Chain \& Biomed of MSF. 


\section{References}

[1] Ahlborg H, Hammar L. Drivers and barriers to rural electrification in Tanzania and Mozambique - Grid-extension, off-grid, and renewable energy technologies. Renew Energy 2014;61:117-24. doi:10.1016/j.renene.2012.09.057.

[2] Borhanazad H, Mekhilef S, Saidur R, Boroumandjazi G. Potential application of renewable energy for rural electrification in Malaysia. Renew Energy 2013;59:210-9.

doi:10.1016/j.renene.2013.03.039.

[3] Adaramola MS, Agelin-Chaab M, Paul SS. Analysis of hybrid energy systems for application in southern Ghana. Energy Convers Manag 2014;88:284-95. doi:10.1016/j.enconman.2014.08.029.

[4] Campana PE, Li H, Zhang J, Zhang R, Liu J, Yan J. Economic optimization of photovoltaic water pumping systems for irrigation. Energy Convers Manag 2015;95:32-41. doi:10.1016/j.enconman.2015.01.066.

[5] Edwin M, Joseph Sekhar S. Techno-economic studies on hybrid energy based cooling system for milk preservation in isolated regions. Energy Convers Manag 2014;86:1023-30. doi:10.1016/j.enconman.2014.06.075.

[6] Ismail MS, Moghavvemi M, Mahlia TMI. Design of an optimized photovoltaic and microturbine hybrid power system for a remote small community: Case study of Palestine. Energy Convers Manag 2013;75:271-81. doi:10.1016/j.enconman.2013.06.019.

[7] Ismail MS, Moghavvemi M, Mahlia TMI. Techno-economic analysis of an optimized photovoltaic and diesel generator hybrid power system for remote houses in a tropical climate. Energy Convers Manag 2013;69:163-73. doi:10.1016/j.enconman.2013.02.005.

[8] Ismail MS, Moghavvemi M, Mahlia TMI. Genetic algorithm based optimization on modeling and design of hybrid renewable energy systems. Energy Convers Manag 2014;85:120-30. doi:10.1016/j.enconman.2014.05.064.

[9] Suresh Kumar U, Manoharan PS. Economic analysis of hybrid power systems (PV/diesel) in different climatic zones of Tamil Nadu. Energy Convers Manag 2014;80:469-76. doi:10.1016/j.enconman.2014.01.046.

[10] Higier A, Arbide A, Awaad A, Eiroa J, Miller J, Munroe N, et al. Design, development and deployment of a hybrid renewable energy powered mobile medical clinic with automated modular control system. Renew Energy 2013;50:847-57. doi:10.1016/j.renene.2012.07.036.

[11] For O, Energy I, At S. Powering health 2008. 
[12] Sinha S, Chandel SS. Review of software tools for hybrid renewable energy systems. Renew Sustain Energy Rev 2014;32:192-205. doi:10.1016/j.rser.2014.01.035.

[13] Mohammed YS, Mustafa MW, Bashir N. Hybrid renewable energy systems for off-grid electric power: Review of substantial issues. Renew Sustain Energy Rev 2014;35:527-39. doi:10.1016/j.rser.2014.04.022.

[14] Sharafi M, ElMekkawy TY. Stochastic optimization of hybrid renewable energy systems using sampling average method. Renew Sustain Energy Rev 2015;52:1668-79. doi:10.1016/j.rser.2015.08.010.

[15] Bernal-Agustín JL, Dufo-López R. Simulation and optimization of stand-alone hybrid renewable energy systems. Renew Sustain Energy Rev 2009;13:2111-8. doi:10.1016/j.rser.2009.01.010.

[16] Akikur RK, Saidur R, Ping HW, Ullah KR. Comparative study of stand-alone and hybrid solar energy systems suitable for off-grid rural electrification: A review. Renew Sustain Energy Rev 2013;27:738-52. doi:10.1016/j.rser.2013.06.043.

[17] Fadaee M, Radzi M a M. Multi-objective optimization of a stand-alone hybrid renewable energy system by using evolutionary algorithms: A review. Renew Sustain Energy Rev 2012;16:3364-9. doi:10.1016/j.rser.2012.02.071.

[18] Kamjoo A, Maheri A, Putrus G a. Chance constrained programming using non-Gaussian joint distribution function in design of standalone hybrid renewable energy systems. Energy 2014;66:677-88. doi:10.1016/j.energy.2014.01.027.

[19] Arun P, Banerjee R, Bandyopadhyay S. Optimum sizing of photovoltaic battery systems incorporating uncertainty through design space approach. Sol Energy 2009;83:1013-25. doi:10.1016/j.solener.2009.01.003.

[20] Kamjoo A, Maheri A, Dizqah AM, Putrus G a. Multi-objective design under uncertainties of hybrid renewable energy system using NSGA-II and chance constrained programming. Int J Electr Power Energy Syst 2016;74:187-94. doi:10.1016/j.ijepes.2015.07.007.

[21] Maheri A. A critical evaluation of deterministic methods in size optimisation of reliable and cost effective standalone hybrid renewable energy systems. Reliab Eng Syst Saf 2014;130:159-74. doi:10.1016/j.ress.2014.05.008.

[22] Maheri A. Multi-objective design optimisation of standalone hybrid wind-PV-diesel systems under uncertainties. Renew Energy 2014;66:650-61. doi:10.1016/j.renene.2014.01.009.

[23] Dufo-López R, Lujano-Rojas JM, Bernal-Agustín JL. Comparison of different lead-acid battery lifetime prediction models for use in simulation of stand-alone photovoltaic systems. Appl Energy 
2014;115:242-53. doi:10.1016/j.apenergy.2013.11.021.

[24] Schiffer J, Sauer DU, Bindner H, Cronin T, Lundsager P, Kaiser R. Model prediction for ranking lead-acid batteries according to expected lifetime in renewable energy systems and autonomous power-supply systems. J Power Sources 2007;168:66-78. doi:10.1016/j.jpowsour.2006.11.092.

[25] Jain P. Wireless Body Area Network for Medical Healthcare. IETE Tech Rev 2011;28:362. doi:10.4103/0256-4602.83556.

[26] Dufo-López R. iHOGA (improved Hybrid Optimization by Genetic Algorithms) software 2015.

[27] Dufo-López R, Bernal-Agustín JL. Design and control strategies of PV-Diesel systems using genetic algorithms. Sol Energy 2005;79:33-46. doi:10.1016/j.solener.2004.10.004.

[28] Dufo-López R, Bernal-Agustín JL, Contreras J. Optimization of control strategies for stand-alone renewable energy systems with hydrogen storage. Renew Energy 2007;32:1102-26. doi:10.1016/j.renene.2006.04.013.

[29] Krishnan V, McCalley JD, Henry S, Issad S. Efficient Database Generation for Decision Tree Based Power System Security Assessment. IEEE Trans Power Syst 2011;26:2319-27. doi:10.1109/TPWRS.2011.2112784.

[30] Krishnan V, McCalley JD. Importance Sampling Based Intelligent Test Set Generation for Validating Operating Rules Used in Power System Operational Planning. Power Syst IEEE Trans 2013;28:2222-31. doi:10.1109/TPWRS.2012.2235187.

[31] Kalos MH, Whitlock P a. Monte Carlo Methods. 2008th ed. WILEY-VCH; 2008. doi:10.1002/9783527626212.

[32] Driels MR, Shin YS. Monterey, California 2004.

[33] Mendo L, Hernando JM. A simple sequential stopping rule for Monte Carlo Simulation. IEEE Trans Commun 2006;54:231-41. doi:10.1109/TCOMM.2005.863780.

[34] Skarstein O, Uhlen K. Design Considerations with Respect to Long-Term Diesel Saving in Wind/Diesel Plants. Wind Eng 1989;13:72-87.

[35] NASA Atmospheric Science Data Center n.d.

[36] Graham VA, Hollands KGT. A method to generate synthetic hourly solar radiation globally. Sol Energy 1990;44:333-41. doi:10.1016/0038-092X(90)90137-2.

[37] World solar data n.d. 
[38] Labed S. "Contribución al desarrollo de métodos para la electrificación rural fotovoltaica a gran escala”. PhD Thesis. Universidad Politécnica de Madrid . Escuela Técnica Superior de Ingenieros de Telecomunicación. 2004.

[39] Doctors Without Borders n.d. 